\title{
Design and Development of Engineered Fire Suppression System
}

\author{
Dr. M. K. Marichelvam ${ }^{1 *}$, Mr. K. Mahes waran² \\ ${ }^{1,2}$ Department of Mechanical Engineering, Mepco Schlenk Engineering College, Sivakasi, Tamilnadu, India \\ *Corresponding Author: Dr. M. K. Marichelvam, Department of Mechanical Engineering, Mepco chlenk \\ Engineering College, Sivakasi, Tamilnadu, India
}

\begin{abstract}
Fire is one of the important element in nature without which world will not function. Despite of all the benefits still the loss occurred due to fire is unaccountable. Due to the fire incident so much of life, property are damaged heavily. So every step is taken universally to control the fire. Fire occurring is a combination of Oxygen, Fuel, and Heat. Fire extinguishers are used to extinguish the fire. Commercially different types of fire extinguishers are used based on the applications. [1]Most of the accidents occurred due to improper handling offire extinguishers. Fire fighters are affected heavily by severe injury and loss of life in order to reduce accidents while firefighting. This paper attempts to partially replace human by semiautomated machine for the firefighting operations. The firefighting process involves, fire protection system by attaching a small nozzle to the moving arm and is controlled by semi-automatic process that replaces the firefighter to perform the firefighting activities. This firefighting system is to reduce the direct contact of the fire fighter to the fire hazards and also to reduce consumption of water during firefighting process. Fire fighters overcomes dangerous situations in extinguishing the fire and while rescuing the victims. This semiautomatic fire suppression system will evaluate the fire fighter to execute at a distance from fire which give comfort and lower risk to the firefighting people.
\end{abstract}

Keywords: semi-automatic firefighting system, 3 axis rotation fire hose and RF wireless remote control.

\section{INTRODUCTION}

Fire is the rapid oxidation of a material in the exothermic chemical process of combustion, releasing heat, light, and various reaction products. Slower oxidative processes like rusting or digestion are not included by this definition. At a certain point in the combustion reaction, called the ignition point, flames are produced. The flame is the visible portion of the fire. Flames consist primarily of carbon dioxide, water vapor, oxygen and nitrogen. If hot enough, the gases may become ionized to produce plasma. Depending on the substances alight, and any impurities outside, the color of the flame and the fire's intensity will be different. Fire in its most common form can result in conflagration, which has the potential to cause physical damage through burning. Fire is an important process that affects ecological systems around the globe. The positive effects of fire include stimulating growth and maintaining various ecological systems. Fire has been used by humans for cooking, generating heat, light, signaling, and propulsion purposes. The negative effects of fire include hazard to life and property, atmospheric pollution, and water contamination. If fire removes protective vegetation, heavy rainfall may lead to an increase in soil erosion by water. Also, when vegetation is burned, the nitrogen it contains is released into the atmosphere, unlike elements such as potassium and phosphorus which remain in the ash and are quickly recycled into the soil. This loss of nitrogen caused by a fire produces a long- term reduction in the fertility of the soil, which only slowly recovers as nitrogen is "fixed" from the atmosphere by lightning and by leguminous plants such as clover.

A firefighting system is probably the most important of the building services, as its aim is to protect human life and property, strictly in that order. It consists of three basic parts, A large store of water in tanks, either underground or on top of the building, called fire storage tanks, A specialized pumping system, A large network of pipes ending in either hydrants or sprinklers (nearly all buildings require both of these systems).Engineered Fire Suppression Systems are design specific. Engineered systems are usually for larger installations where the system is designed for the particular application. Examples include marine and land vehicle applications, computer clean rooms, public and private buildings, industrial paint lines, dip tanks and electrical switch rooms. Pre-Engineered 
Fire Suppression Systems use pre-designed elements to eliminate the need for engineering work beyond the original product design. Typical industrial solutions use a simple wet or dry chemical agent, such as Potassium Carbonate or Mono Ammonium Phosphate (MAP), to protect spaces such as paint rooms and booths, storage areas and commercial kitchens. A small number of residential designs have also emerged that typically employ water mist with or without a surfactant additive, and target retrofit applications where the risk of fire or fire injury is high but where a conventional fire sprinkler system would be unacceptably expensive.

This paper attempts to replace human for the firefighting operations. The firefighting semiautomatic system is one that acts as a fire protection system by attaching a small nozzle to the semiautomatic arm and is controlled by semi-automatic process. Which replace the fire fighter to performing the firefighting activities? In this firefighting system, this semi-automatic system is able to reduce the direct contact of the fire fighter to the fire hazards and also reduce wastage water and operating time. Semi- automatic fire fighting system is one of the fast ever growing technological fields in suppression. Semi- automatic are [11] designed to partially replace the human factor from dangerous work and also to act in accessible environmental condition. The use of semi-automatics may be applied various industries. The need for Fire extinguisher Semi-automatic can extinguish a fire on its own a longer period. With the implementation such a device, people and other property can be saved. Fire fighters faces dangerous situations when extinguishing fires and rescuing victims. The semi-automatic arm can function by itself or be controlled from a distance and to do firefighting activities without the involvement of human being at risk area. In this paper, a semi-automatic cost effective prototype of a firefighting system for the control of fire has been designed and fabricated for fighting against the fire.

\section{A. Design Goals}

It is unnecessary for firefighters to expose themselves under the dangerous Condition. The motivation of this research is to improve the situation of fire location for the firemen. Therefore the objective of this research illustrated in points below

1. Building a moving arm with 3 degree of freedom hose arm one Cartesian and two rotational for the spray hose that is controlled from remote by fire specialist.

2. This Fire Fighting System should be able to access the various areas and step on some obstacles which require specific design for the mechanism of moving including climbing stairs, among many designs for such robots mechanism the proper decision was to going on the tank chain design since it's more suitable with our requirements.

3. A multifunction radio transmitter and receiver are needed to allow the fireman specialist to control the various actions that is required to react properly to the fire using the hose to extinguish it.

4. The remote communication system is connected to a remote computer to control the robot and processing the incoming data.

5. With the help of such system which is shown in Figure 1, the fire men work will be easier and effective regardless the main reason which will make it more safety for them keeping them outside the zone of dangerous ring.

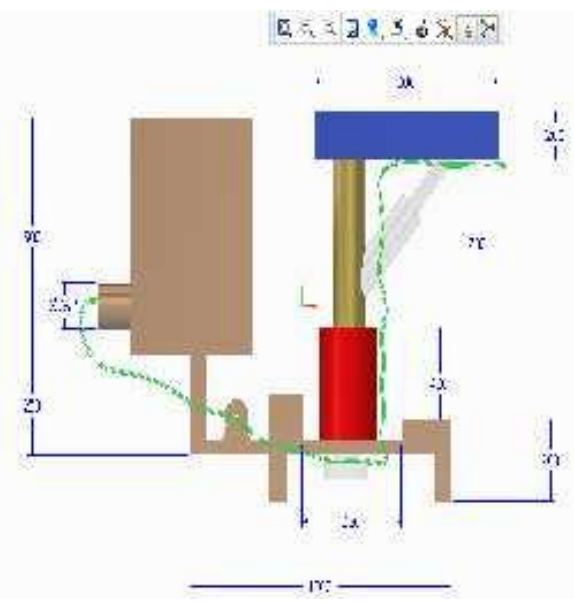

Figure1. Design of semi-automatic system 


\section{B. Manipulator Design and Mechanism}

Time to accomplish any mission for any moving system depends on the system capability and its degrees of freedom, many Firefighting systems had no [8] manipulators to guide the extinguisher hose to the direction of fire, they are depending on relocate the direction of the robot itself towards the fire, where the extinguishing hose is fixed in front of the system.

To avoid this obstacle decision made to give $\mathrm{t}$ some degrees of freedom by adding an extinguisher manipulator to control the space around the firefighting system instead of relocate the system each time. And since tries made to minimize the robot load which cannot be done unless the consisting parts minimized, and that's mean minimizing the degrees of freedom. After discussing the demands of Kirkuk city fire department clear idea get to mind, that the manipulator should consist of 3 degrees of freedom, two rotational and one Cartesian motion [12].

\section{FABRICATION}

It consists of selection of material and components required. The fabrication is to make a miniature product of automatic fire fighting system. The following components are used for fabrication.

- Base plate (chassis).

- Rack \& pinion ladder

- Manipulator

- De motor

- piping system with suitable nozzle

- Electrical \& electronics device (battery, remote control, wires)

Initially fabrication process starts with selection of material for the frame. Material has to withstand heat and also self-weight of the system. The mild steel is selected as a frame material and it is cut as per the drawing. Plain sheet is metal placed over the frame for fitting the moving arm motor set up.

The moving arm base welded with frame setup vertically. [10]DC motor $12 \mathrm{~V}$ is fitted with the arm for the rotational motion. Rack and pinion set is to be welded over the arm for the up and down motion. At the top of the arm, stepper motor with the range of $100 \mathrm{rpm}$ is fitted for another Cartesian motion and it will be actuated by relay switch. It's a step by step movement.

Domestic water [7] pump is with 0.5 HP fitted at the left side of the frame it is used to suction and delivery of water. Pressure varies from 3 to 4 bar. 10 liter water tank is to fitted at $100 \mathrm{~cm}$ height from the frame. One inch forestry fire type hose is used based on the standard.

Four plastic type wheels are attached for the movement of the firefighting system. DC motors are actuated by $12 \mathrm{~V}$ battery power supply. Trolley is moved manually. Pump powers $230 \mathrm{~V}$ supply. Hose pipe is fitted with the moving arm. At the end of the hose pipe nozzle. The wireless RF [10] controller arms are remotely operated at periphery of 200 meter distance. Painting is coated over the components to avoid corrosion. Electronic circuits are inbuilt in the frame setup of the system which is shown in Figure 2.

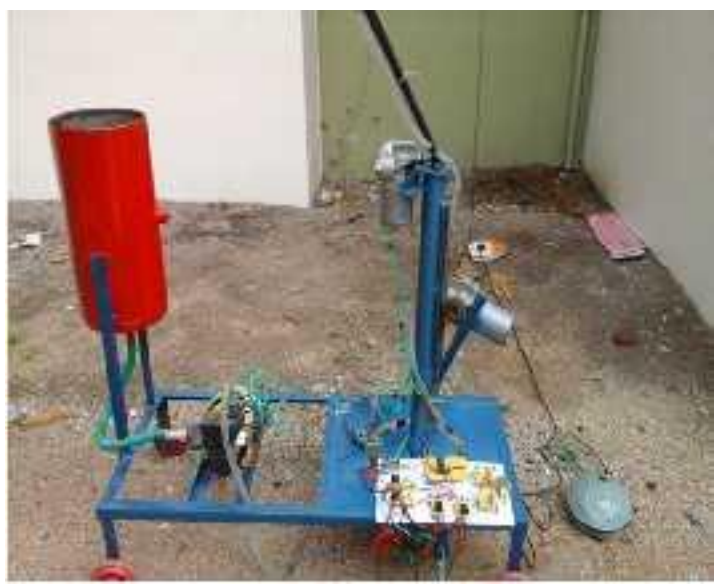

Figure2. Fabrication setup of semi-automatic system 


\section{EXPERIMENTAL WORK}

\section{A. Wood Crib Test}

As per UL 711 and NFPA 18 standard tests were conducted to ensure the extinguishing time and water consumption [2]. We have conducted a extinguishing time test and water consumption rate for firefighting operation. Extinguishment time to be calculated by using the wood crib sample test shown in Figure 3[3]. Fire suppression is done by normal water flow and nozzle water flow compare both the results to find the performance of a system. The dimensions of a wood crib system as per fire flow calculation $80 x 60 \mathrm{~cm}$ and this shown in Figure 4 [4]. From this test extinguishing time is to be calculated.

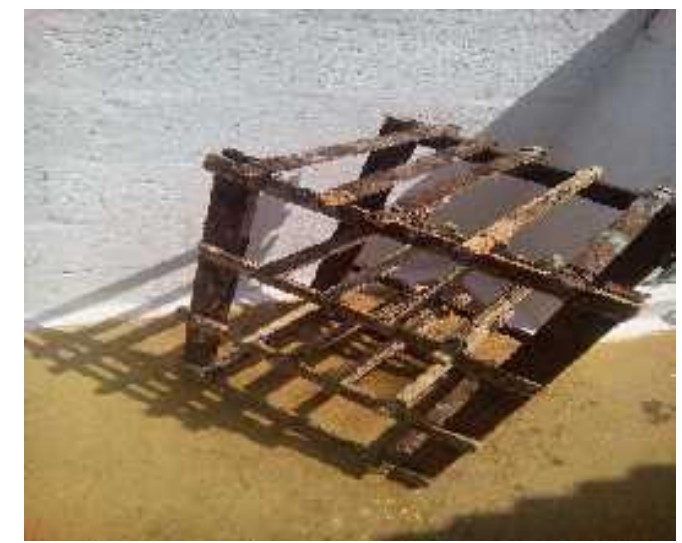

Figure3. Wood crib sample

Fire extinguishment test (Normal flow):
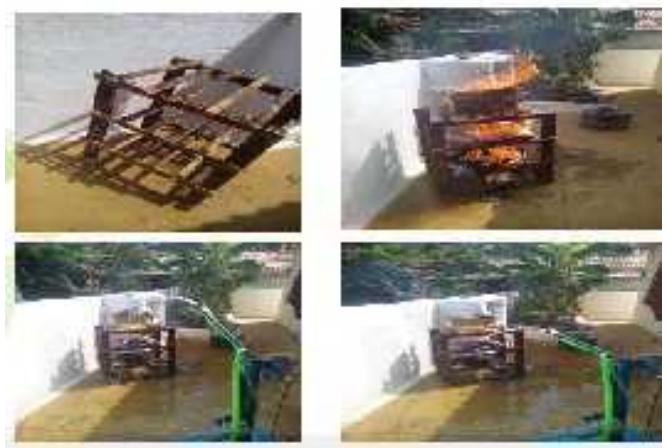

Figure4. Extinguishment by normal flow

\section{B. Fire Flow}

Fire fighters need to ensure sufficient water is available to contain and extinguish the fire [5]. The Needed Fire Flow Formula is a helpful tool to determine total fire flow necessary. The fire fighter needs to determine the flow required and communicate the need to the Driver Operator. The nozzle plays major role in Extinguishment of fire which is shown in Figure 5 and the Basic Formula is given below.

\section{Fire extinguishment test (Nozzle flow):}
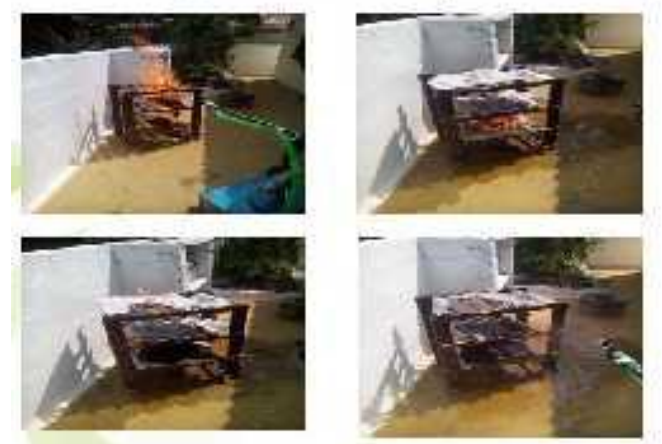

Figure5. Extinguishment by nozzle flow 
Needed fire flow $=[($ length $\mathrm{x}$ width $) \div 3] \mathrm{x}$ (percentage of involvement) Fire flow $=(30 * 80) / 3$

$=800 \mathrm{gpm}$

For $25 \%$ of involvement of fire,

$=800 * 25 \%$

$=800 * 0.25$

$=200 \mathrm{gpm}$ (or) $12.618 \mathrm{l} / \mathrm{s}$

Based on the fire flow formula amount of water required for fire suppression is 12.618 litres.

\section{RESULTS AND DISCUSSION}

\section{A. Modified Firefighting Sys tem}

In the firefighting system the tank system and electrical circuit board are modified based on the test method which is shown in Figure 6. Water storage tank is to be modified due to unbalancing of a system with loaded condition.

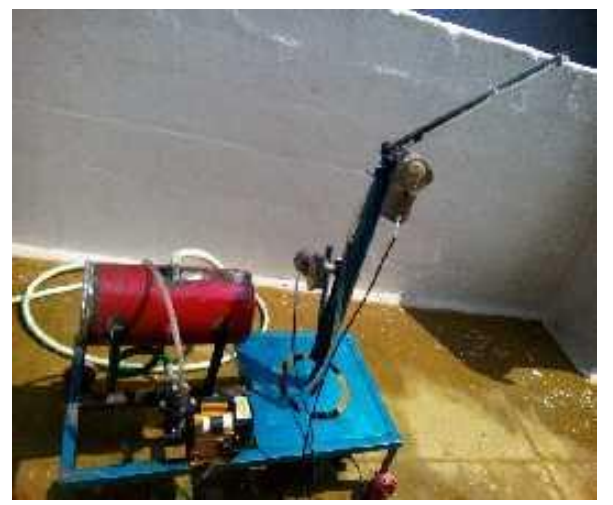

Figure6. Modified semi-automatic system

\section{B. Wood Crib Test}

From this test extinguishment time between normal flow and nozzle flow of a system is to be plotted. Extinguishment time in seconds is shown in Figure 7.

Infer from the chart extinguishment time of nozzle flow (33s) is less than normal flow (39s) of system. According to safety factor nozzle flow is safer than normal flow for firefighting.

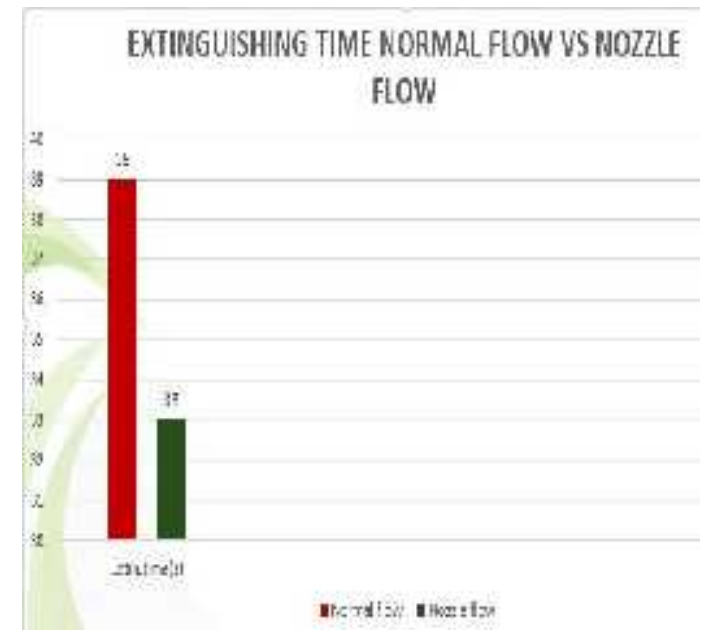

Figure7. Extinguishment time for Normal flow vs Nozzle flow

\section{Water Discharge Rate}

The basic method for controlling building fires by fire departments is through the use of water, which is typically applied with manual hose lines or water monitors as shown in Figure 8. From this plot water discharge rate is compared with both the models. For normal flow (10lit), for nozzle flow (4.5lit).so the water discharge rate is reduced in the nozzle flow type of system. it will be suitable to minimizing the scarcity of water during firefighting. 


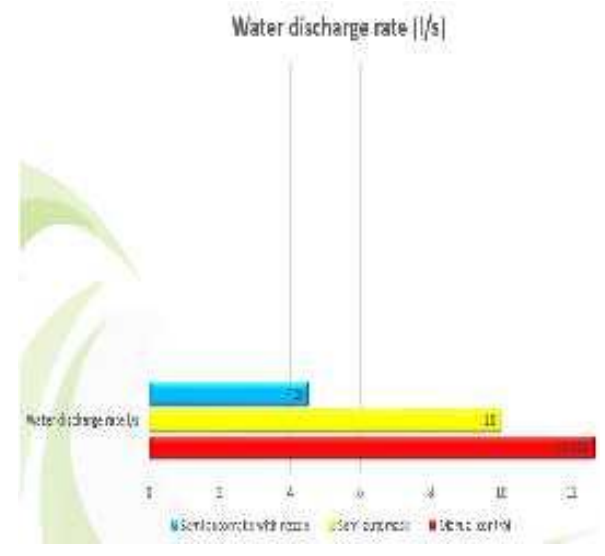

Figure8. Water discharge for Normal flow vs Nozzle flow

\section{CONCLUSION}

The paper deals with the various hazards faced by fire fighters during a fire. The firefighting techniques and situations are analyzed at various criteria's and all possible aspects to find a method or solution to avoid fire hazards faced by fire fighters. The extinguishment of fire is a prior it's firefighting to prevent people and their valuable things as soon as possible but safety of fire fighters also plays more important while fighting a fire. In this paper the design of firefighting system is made to be controlled by remote control to protect the fire fighters against various hazards faced by them during firefighting. The equipment can move the nozzle containing shaft vertically up and down according to the situation and the place where fire hazards take place. It is also capable of rotating at all angles and extinguishing the fire surrounding it. The water is forced against fire with the help of nozzle placed in remote controlled fire extinguishing system which will be effective and safe. This firefighting method can be used for various fire hazards including common household fires and ordinary fires of materials like paper, wood, etc., this firefighting equipment can be used in wide areas of applications to prevent fires at various different situations as well as to protect the fire fighters against the fire hazards.

\section{REFERENCES}

[1] Kong, P. W., Suyama, J., \& Hostler, D. (2013). A review of risk factors of accidental slips, trips, and falls among firefighters. Safety science, 60, 203-209.

[2] Tamanini, F. (2010). Defining the effects of ambient conditions in large-scale fire tests. Experimental Thermal and Fluid Science, 34(3), 404-411.

[3] Himoto, K., \& Tanaka, T. (2012). A model for the fire-fighting activity of local residents in urban fires. Fire safety journal, 54, 154-166.

[4] Alarifi, A. A., Dave, J., Phylaktou, H. N., Aljumaiah, O. A., \& Andrews, G. E. (2014). Effects of firefighting on a fully developed compartment fire: Temperatures and emissions. Fire Safety Journal, 68, 7180 .

[5] Grim wood, P., \& Sanderson, I. A. (2015). A performance based approach to defining and calculating adequate firefighting water using s. 8.5 of the design guide BS PD 7974: 5: 2014 (fire service intervention). Fire Safety Journal, 78, 155-167.

[6] Chow, C. L., \& Ki Chow, W. (2009). Fire safety aspects of refuge floors in supertall buildings with computational fluid dynamics. Journal of Civil Engineering and Management, 15(3), 225-236.

[7] Neal, A. J. (2012). Tips for Selecting DC Motors for Your Mobile Robot.

[8] Howie Choset, An Introduction to Robot Kinematics, Carnegie Mellon, the robotics institution, 2007.

[9] National Instruments RF \& Communications Handbook, National Instruments Germany GmbH Konrad Celtis-Str. 7981369 München

[10] Jim Muccioli, DC Motor EMI Suppression, Ford Motor Company July 27, 2004.

[11] Hongke Xu, Hao Chen, Chao Cai, Xunzhao Guo, Jianwu Fang, Design and Implementation of Mobile Robot Re- mote Fire Alarm System, 2011 International Conference on Intelligence Science and Information Engineering, Zhu Sun School of Electronic and Control Engineering Chang'an University Xi'an, 710064, China.

[12] Omesh Kumar M, Implementing 360 rotation of Robot on its axis, International Journal of Computer Applica- tions (0975 - 8887), Volume 45- No.17, May 2012, En- gineering College Ghaziabad, India. 


\section{AUTHORS' B IOGRAPHY}

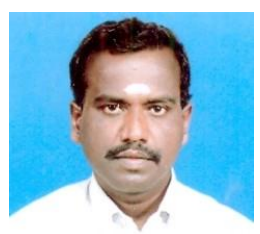

M. K. Marichelvam, received his B.E. degree in Mechanical Engineering from Madurai Kama Raj University, Madurai, India, in 2000. He has obtained a Masters in Engineering in Industrial Engineering from Madurai Kama Raj University, Madurai, India, in 2002. He has obtained Ph.D. in Mechanical Engineering from Anna University, Chennai, India in 2015. He is currently working as Assistant Professor (Sr. Grade) in Mechanical Engineering Department, Mepco Schlenk Engineering College, Sivakasi, India. His active areas of interests are Manufacturing Scheduling, Multi-objective optimization, Industrial and Production Management and optimization techniques. He has published many research papers in the Journals of International repute. He has presented papers at several international conferences.

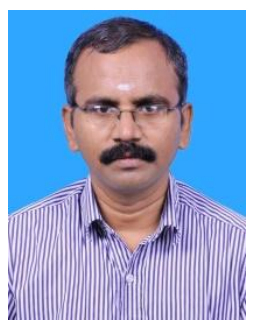

Mr. K. Maheswaran, received his B.Tech, degree in Rubber Technology form Anna University, Chennai, Tamilnadu, India, in 1991. He has obtained a Masters in Engineering in Industrial Safety Engineering from Anna University, Chennai, India, in 2008. He is Pursuing his Ph.D. in Anna University, Chennai; He is currently working as Assistant Professor (Sr. Grade) in Mechanical Engineering Department, Mepco Schlenk Engineering College, Sivakasi, India. His active areas of interests are Safety Engineering and Environmental studies. He has published many research papers in the International journal. He has wide experience in industries experience of various field.

Citation: M. K. Marichelvam et.al. (2018)" Design and Development of Engineered Fire Suppression System", International Journal of Modern Studies in Mechanical Engineering, 4(1), pp.17-23. DOI: http://dx.doi. org/10.20431/2454-9711.0401003

Copyright: (C) 2018 M. K. Marichelvam, This is an open-access article distributed under the terms of the Creative Commons Attribution License, which permits unrestricted use, distribution, and reproduction in any medium, provided the original author and source are credited. 